\title{
A new method for testing the interfacial shear properties between rock and early-aged shotcrete
}

\author{
Jian-guo Liu, Xiao-jun Zhou, Wei Zhao, Yu-sheng Shen, Qing-hua Xiao
}

Key Laboratory of Transportation Tunnel Engineering, Ministry of Education, School of civil engineering, Southwest Jiaotong University, Chengdu 610031, China

xqbbp@bome.swjtu.edu.cn

ABSTRACT. A new method for testing the interfacial shear properties between early-aged shotcrete and rock was developed in the present study, which was proposed following a new test principle. A new set of mould was also designed and described in detail, as well as the test procedures. The main advantages of the new method were that, the shock and vibration could be eliminated compared with the traditional ones, and made the evaluation on the shear properties of the very early-aged rock-shotcrete interface possible. With the newly developed method, the time-dependent rock-shotcrete interfacial shear properties were addressed. It was found that, the time-dependent shear behaviors of the interface could be regressed by a 3-parameter exponential function with high accuracy. In general, the presented research focused on the description and verification of the new test method, which could provide a new way to evaluate the interfacial shear properties between very early-aged shotcrete and rock for numerical simulations and other uses.

KEYWORDS. Shotcrete-rock interface; New test method; Direct shear test; Time-dependent behaviors; Interfacial shear properties.

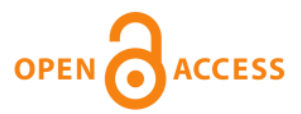

Citation: Liu, J., Zhou, X., Zhao, W., Shen, Y., Xiao, Q., A new method for testing the interfacial shear properties between rock and early-aged shotcrete, Frattura ed Integrità Strutturale, 48 (2019) 161-173.

Received: 20.11 .2018

Accepted: 23.01.2019

Published: 01.04.2019

Copyright: (C) 2019 This is an open access article under the terms of the CC-BY 4.0, which permits unrestricted use, distribution, and reproduction in any medium, provided the original author and source are credited.

\section{INTRODUCTION}

$\mathrm{S}$ hotcrete is widely used as the primary support in underground openings, which can form a skin on the rock surface immediately to protect the rock mass, and thus the host rock can support itself [1]. To form a strong primary support alone or with steel arch, mesh and rock bolt, the interfacial properties between rock and shotcrete are quite important, on which the adhesion and load transferring are dependent [1-4].

Previous studies have revealed that the interaction between rock and shotcrete liner were dependent not only on the properties of rock and shotcrete but also on the interface between them [2, 5-6]. Ansell highlighted the need of accurate interfacial bond strength for numerical analysis [7-8], and various test methods have been developed for reliable and accurate evaluation of the bond strength of rock-shotcrete interface [4, 9-12]. On the other hand, the shear properties of 
rock-shotcrete interface have not attracted so much attention, and only a few tests were performed [13-15], including the interfacial shear strength between shotcrete and different types of rock substrate [13], shear strength and stiffness with different surface profiles of rock substrate [14] and time-dependent variations of the shear properties [15]. It was found that, the samples for direct shear test was quite difficult to be obtained from tunnel site due to rock fractures, shock and vibration during boring, especially for early-aged samples [15]. To assess the interfacial shear properties between rock and early-aged shotcrete, the bond interfaces of the samples should be prepared without being damaged, and making individual samples might be the possible way, like the direct shear tests on rock-concrete interface [16-19].

Given this comprehension, a new direct shear test method was developed through making individual samples, without coring process after shotcreting. A new set of mould was also designed for sample preparation and described in detail, as well as the test procedures. With the newly developed test method, a series of direct shear tests were performed and the interfacial shear properties between early-aged shotcrete and rock substrate were investigated. Then, the time-dependent interfacial shear properties of rock-shotcrete interface were evaluated and regressed with different equations. The failure modes of bond interfaces were discussed, as well as the deficiency of the newly developed test method. The obtained interfacial shear properties could be useful for numerical simulations and other purposes.

\section{IMPROVED TEST METHOD}

$\mathrm{D}$ irect shear test has always been used as the evaluation method for the shear properties of the interface formed by shotcrete and rock. The procedures could be summarized as sample preparation and direct shear test in sequence. In general, the two kinds of rock-shotcrete samples have been used in the previous studies, and the main difference between them was in the sample preparation process. One kind of the previous rock-shotcrete samples were drilled from tunnel sites with a certain period of curing time after the shotcrete was placed [15], while samples in the other kind were drilled in laboratory after pre-processed rock was placed in mould and the shotcrete was sprayed onto the rock surface [14]. It is obvious that the vibration and shock effects on the rock-shotcrete bond interface could not be avoided, which would cause damage to the bond interface, especially when the shotcrete was early-aged.

To overcome the limitation of the methods adopted in the previous studies, a new test method for the evaluation of rockshotcrete interfacial shear properties was proposed, with a main improvement of eliminating the drilling process in the sample preparation. The main principle of the newly developed method was to make individual samples with individual rock cores directly. A new set of mould was used to position rock core and house shotcrete in this method. The individual samples then were arrayed on a special wooden plate for shotcreting (Fig. 1a). After a period of curing time, the sample cells could be disassembled for direct shear test (Fig. 1b).

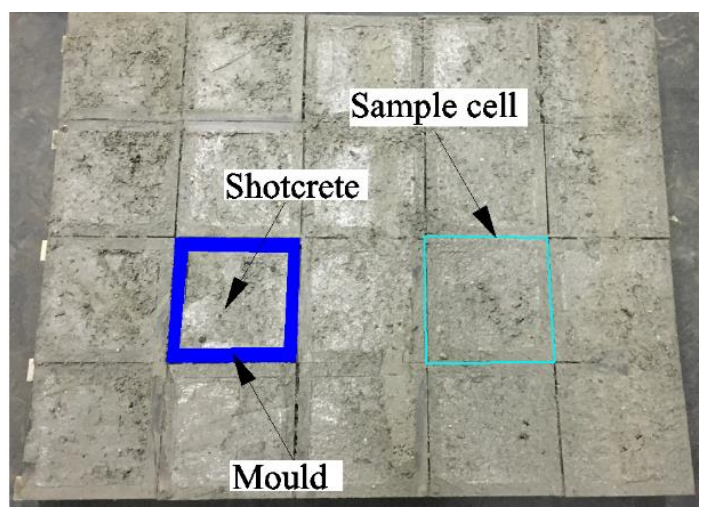

(a)

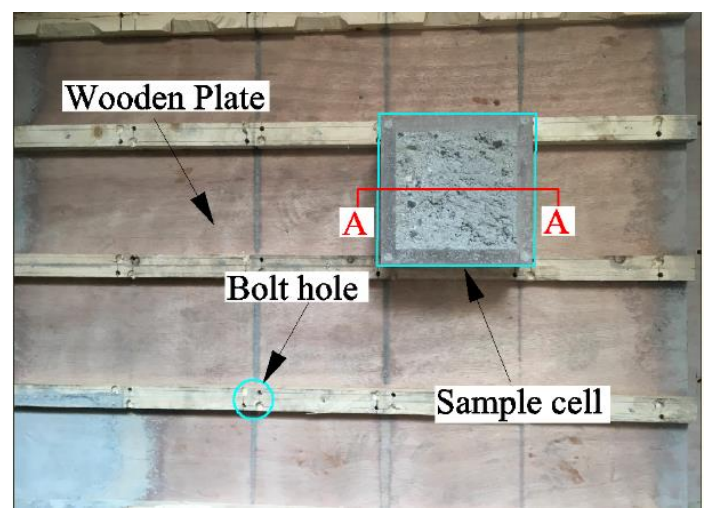

(b)

Figure 1: (a) Sample cells prepared on a wooden plate; (b) Special designed wooden plate with a sample cell attached on.

\section{New test apparatus for sampling}

The mould was the core apparatus for sample preparation, which was made of Perspex and consisted of three main parts: rock core positioning assembly (RCPA), gap ensuring cushion plates (GECP) and shotcrete housing dock (SHD), and the details of the mould are illustrated in Fig. 2a. The heights of the RCPA and SHD were $30 \mathrm{~mm}$ and $43 \mathrm{~mm}$, respectively. The RCPA was used to position the rock core with a $100 \mathrm{~mm}$-diameter cylindrical hole in the center. As shown in Fig. $2 \mathrm{~b}$ (A-A section from Fig. 1b), the bottom surface of rock was a little lower than that of the RCPA (i.e. $1 \mathrm{~mm}$ ). Below the 
RCPA was the gap ensuring cushion plates (GECP), which was used to form a gap between RCPA and SHD, between which the bond interface was generated. The thickness of GECP was $3 \mathrm{~mm}$, with a $\Phi 100 \mathrm{~mm}$ hole designed at the center of it, and the GECP was cut into 2 halves. The SHD was used to house shotcrete spayed onto the bottom surface of rock core, with a main cubic space of $120 \mathrm{~mm} \times 120 \mathrm{~mm} \times 40 \mathrm{~mm}$ at the bottom as well as a cylindrical space of $\Phi 100 \mathrm{~mm} \times 3$ $\mathrm{mm}$ on the top. When shotcrete was spayed into the space form by SHD, GECPs and rock core, the bond interface was formed just between the gap occupied by GECP temporarily, and the GECP would be removed before direct shear test. The outer size of the prepared sample with the mould was $150 \mathrm{~mm} \times 150 \mathrm{~mm} \times 90 \mathrm{~mm}$.

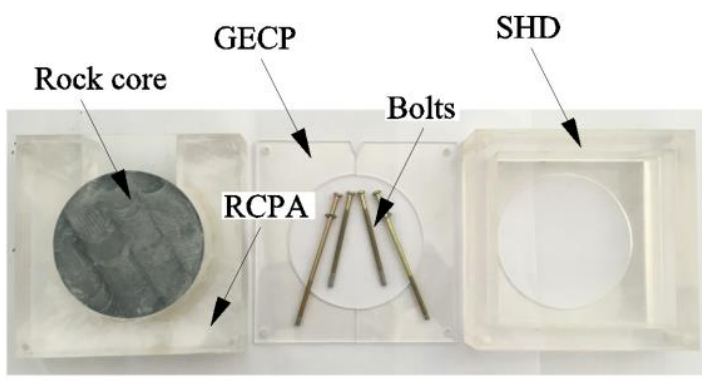

(a)

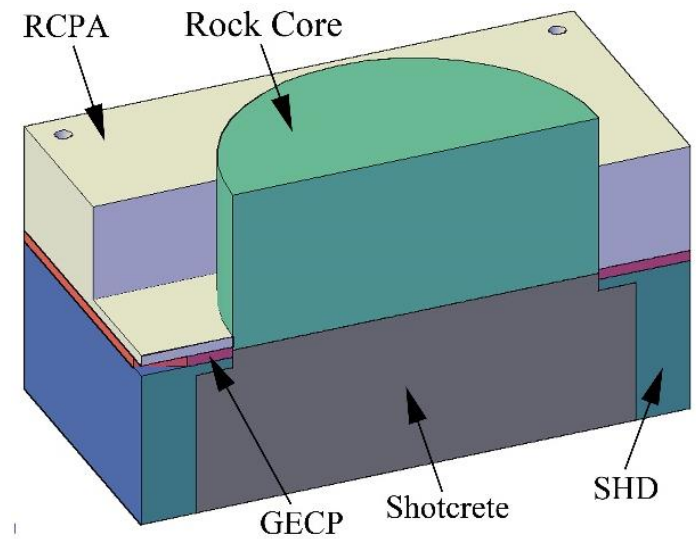

(b)

Figure 2: (a) The assemblies of the mould; (b) Concept map of an individual sample

\section{Materials and test procedures}

Limestone was used as the rock core in the tests, and the uniaxial compressive strength was above $50 \mathrm{MPa}$. The rock core was a 99.5-mm-diameter cylinder with a height of about $45 \mathrm{~mm}$, which was collected from a tunnel site. As has been noted that, the surface roughness of the rock substrate had remarkable influence on the shear behaviors of the interface formed by rock and support material [3, 20], and thus the bottom surface of the rock core used for interface generation purpose was polished through grinding machine, and the surface profiles were controlled to a joint roughness coefficient (JRC) value of $0 \sim 1$. The polishing process is illustrated in Fig. 3.

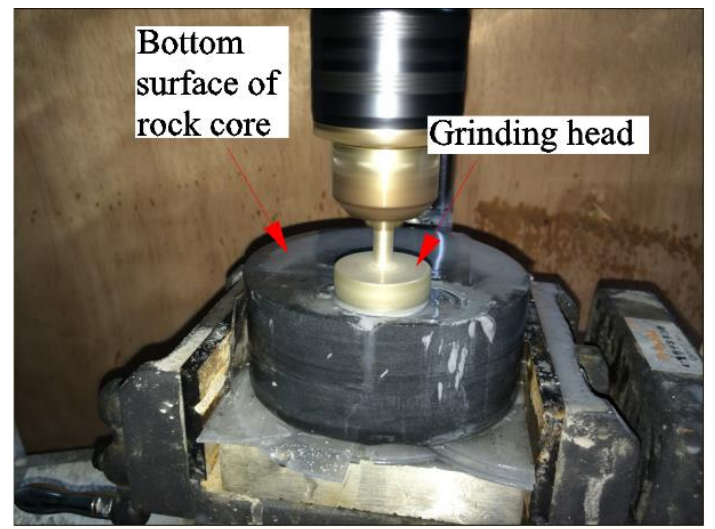

Figure 3: Surface polishing through grinding machine

After the bottom surface was polished, the rock core was placed into the RCPA. To ensure that the bottom surface was just $1 \mathrm{~mm}$ lower than the bottom surface of RCPA, two 1-mm-thick plates were used as the temporary cushion plate (TCP) which contained a hole with a diameter slightly larger than that of the rock core, and the rock then was fixed in the RCPA by hot-melt adhesive and risen on a flat working table as show in Fig. 4 and Fig. 5a,b. Hot-melt adhesive was smeared around the rock core, and resin adhesive of low viscosity was injected into the tiny gap between rock core and RCPA (Fig. 5a, b), so that the rock core could not move or rotate in the following steps. 


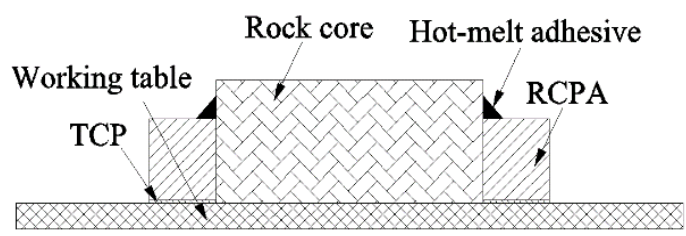

Figure 4: Sketch map of rock core positioning

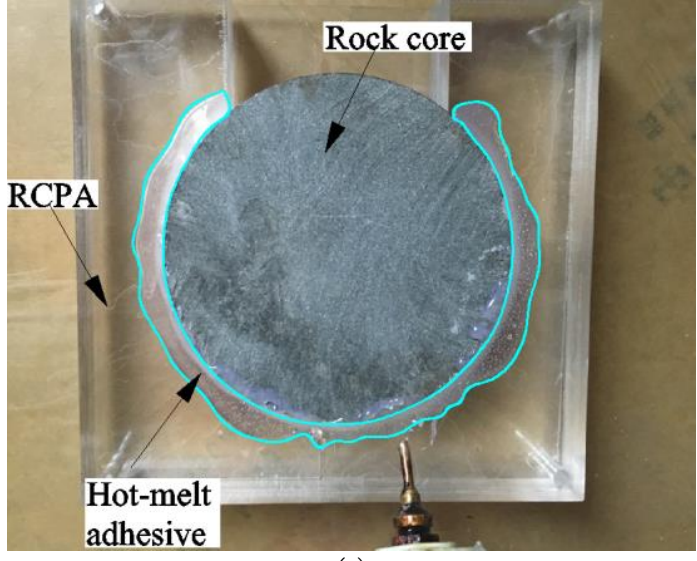

(a)

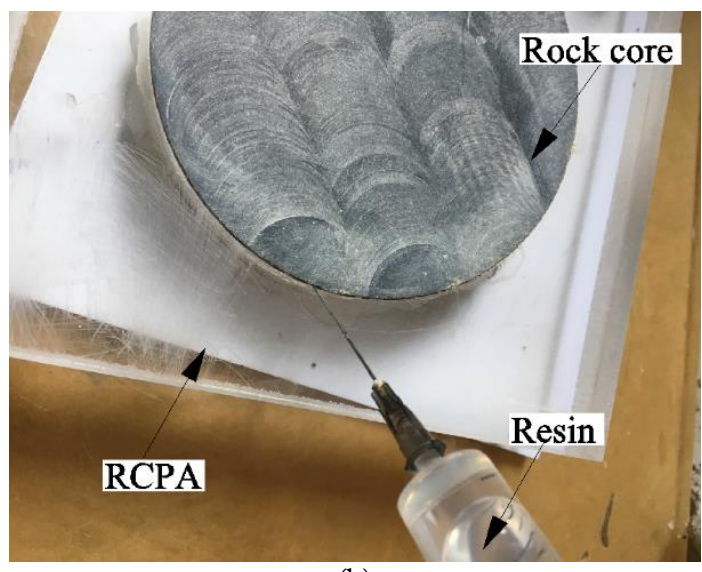

(b)

Figure 5: (a) Rock core fixed in RCPA with hot-melt adhesive; (b) Resin injected into the side gap

When rock core was positioned and fixed, the next step was to assemble a sample cell by fastening the RCPA, GECP and SHD together with bolts. Four bolts were used for each sample cell at the four corners, with two just to fasten the mould assemble and the other two to fasten the mould on a special wooden plate. 20 sample cells were arrayed on each plate for shotcreting (Fig. 1a). When fastening the bolts, an electro drill was used and the moment applied was about $1 \mathrm{~N} \cdot \mathrm{m}$. Besides, a bit of Vaseline was smeared on both sides of the GECP for lubrication.

Shotcrete used in this study was a typical wet mixture for underground primary support purpose, which was designed as C20 type, and its composition used is listed in Tab. 1. P.O. $42.5 \mathrm{R}$ Portland cement was used in the tests, which is a typical cement for underground use. The maximum aggregate size was restricted to $8 \mathrm{~mm}$, which is usually for standard wet-mix shotcrete. Alkali-free accelerator was added at the nozzle during spraying. The wooden plates with sample cells were placed vertically at the foot of an underground opening for shotcreting as shown in Fig. 6a.

\begin{tabular}{cc}
\hline Composition & Weight \\
Cement content $\left(\mathrm{kg} / \mathrm{m}^{3}\right)$ & 460 \\
Water content $\left(\mathrm{kg} / \mathrm{m}^{3}\right)$ & 238 \\
Accelerator $(\mathrm{HX}-10)\left(\mathrm{kg} / \mathrm{m}^{3}\right)$ & 10.2 \\
Aggregates $\left(\mathrm{kg} / \mathrm{m}^{3}\right) 0 \sim 2 \mathrm{~mm}$ & 887 \\
Aggregates $\left(\mathrm{kg} / \mathrm{m}^{3}\right) 0 \sim 8 \mathrm{~mm}$ & 732 \\
Density $\left(\mathrm{kg} / \mathrm{m}^{3}\right)$ & 2321.2 \\
\hline
\end{tabular}

Table 1: Composition of shotcrete used in the tests

Since the bottom surfaces of the samples were not regular and flat after shotcreting, which may cause uneven normal load during testing. So, the surface was flattened immediately after shotcreting. Once the bottom surfaces became even, the samples were moved to an environment of $20^{\circ} \mathrm{C}$ and $32 \% \mathrm{RH}$ for curing. Before direct shear tests, the sample cells were remained on the wooden plates.

The samples were disassembled from the wooden plates after different curing hours, which were $8 \mathrm{~h}, 16 \mathrm{~h}, 24 \mathrm{~h}, 36 \mathrm{~h}, 2 \mathrm{~d}$, $3 \mathrm{~d}, 5 \mathrm{~d}, 7 \mathrm{~d}$ and $14 \mathrm{~d}$ after shotcreting. For each curing time, 8 samples were tested with different normal load. Before testing, the sample cells were disassembled from the wooden plates by loosening the 2 bolts that fixing the cells on the plates, and then the other 2 bolts were loosened so that the gap ensuring cushion plates (GECP) were not fixed in the 
mould any more, and could be removed with a screwdriver in the direction perpendicular to the axis of rock core. The GECP removing process and test-ready sample are shown in Fig. 7a, b.

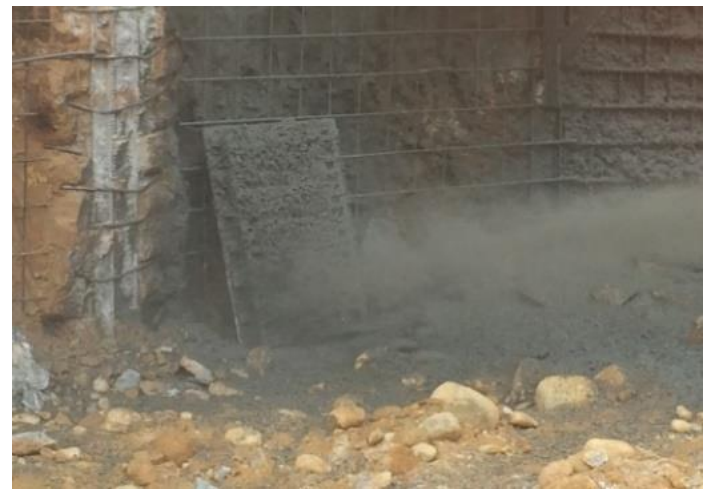

Figure 6: Shotcreting on wooden plates for sampling at tunnel site

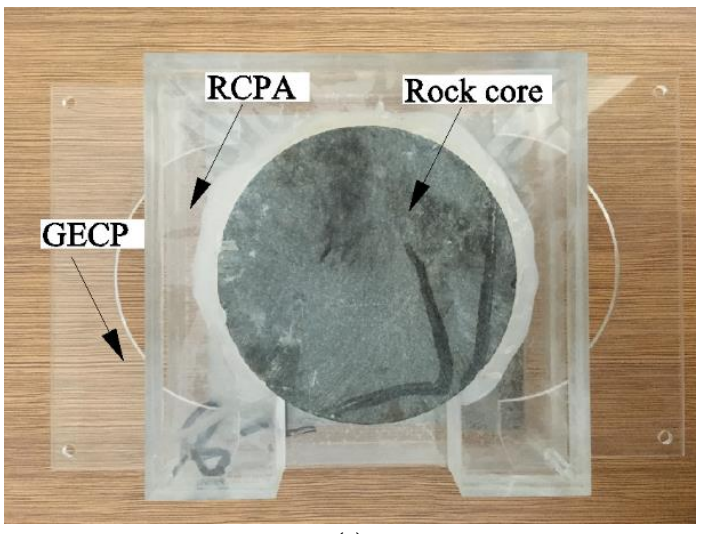

(a)

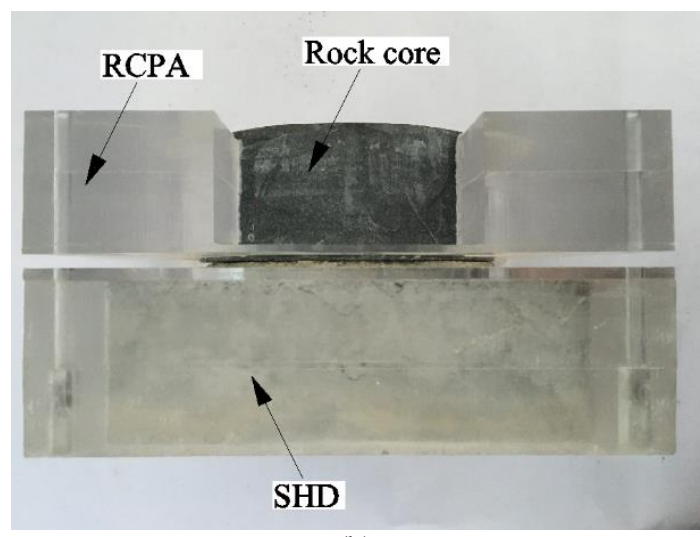

(b)

Figure 7: (a) GECP removed in the lateral direction; (b) Sample ready for test

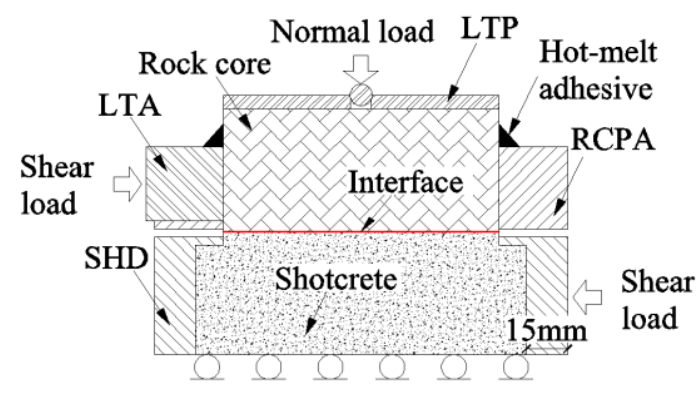

(a)

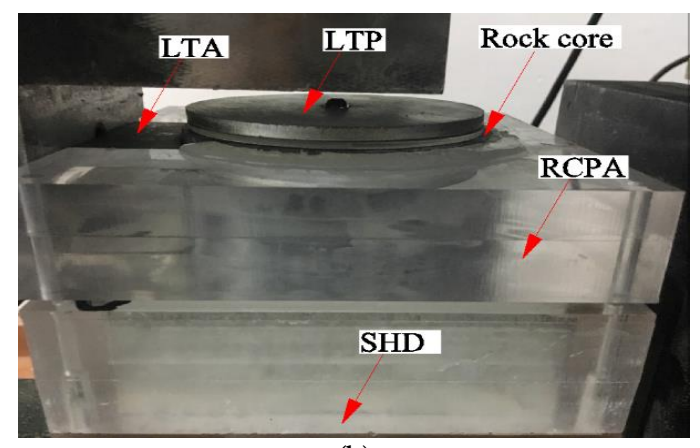

(b)

Figure 8: (a) Shear test diagram; (b) Sample loaded in the test machine and ready for test

The direct shear test with the newly developed apparatus is schematically described in Fig. 8a. Normal load as applied on the top surface of rock core through a steel load transfer plate (LTP). Shear load was applied on the right outer side of SHD by the test machine. Since shotcrete was enwrapped in the SHD, and shear load on the right boundary was the only lateral force applied on SHD, the shear load during test could be transferred to shotcrete body and to the bond interface in sequence. The main difference between the new test method and the previous ones was that, some parts of the mould in the sampling process were remained during the test [5, 14-15]. As the mould was made of Perspex, and the strain of the mould could not be neglected when subjected to shear load, which could lead to inaccurate evaluation on the shear 
properties of the bond interface, especially for the shear stiffness. A load transfer assembly (LTA) made of steel was installed in the gap of the RCPA to bear the shear load from the shear test machine and to transfer the load to the lateral surface of rock core. Shear load was applied on the right side of the Perspex mould. Besides, a steel load transfer plate (LTP) was placed on the top of rock core to make sure that the normal load could be applied evenly (Fig. 8b).

The samples were tested on the typical rock shear test machine that had shear and normal load capacities of $500 \mathrm{kN}$ and $300 \mathrm{kN}$, respectively, with a resolution of $0.01 \mathrm{kN}$. The shear speed and data sampling interval were set at $0.1 \mathrm{kN} / \mathrm{s}$ and 10 ms, respectively. The servo controlled hydraulic test machine, presented in Fig. 9, had four LVDTs to monitor the vertical displacement and two LVDTs for the shear displacement.

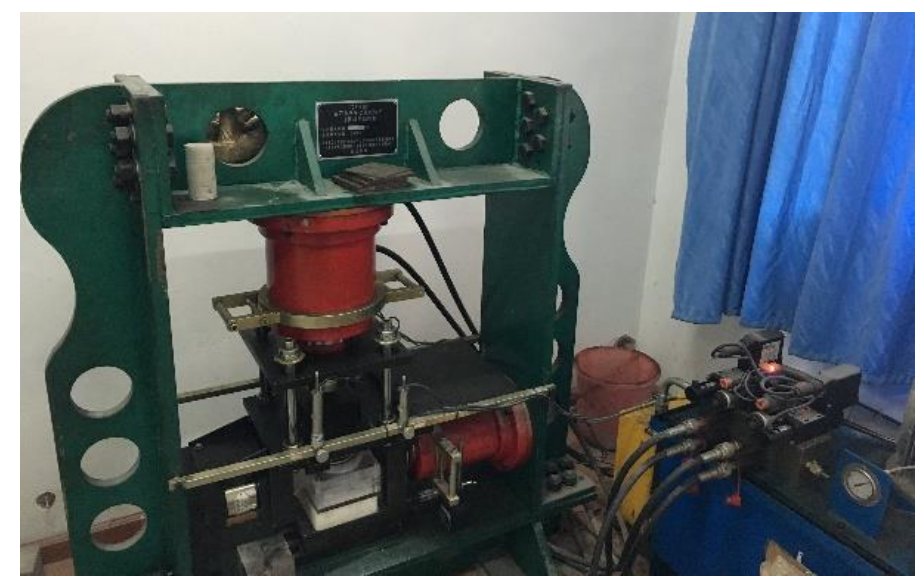

Figure 9: YDS-2 type rock shear testing machine

\section{RESULTS AND DISCUSSION}

7 he shear properties were presented in following with failure modes of the interfaces, and the time-dependent shear cohesion and frictional angle of the interface as well as the shear stiffness were discussed in detail. As the compressive strength of early-aged shotcrete was quite small, the average normal loads in the tests for different curing time were different.

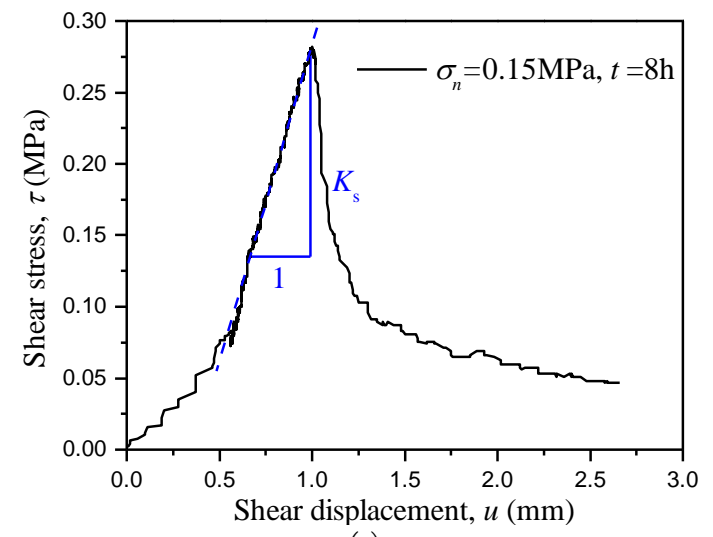

(a)

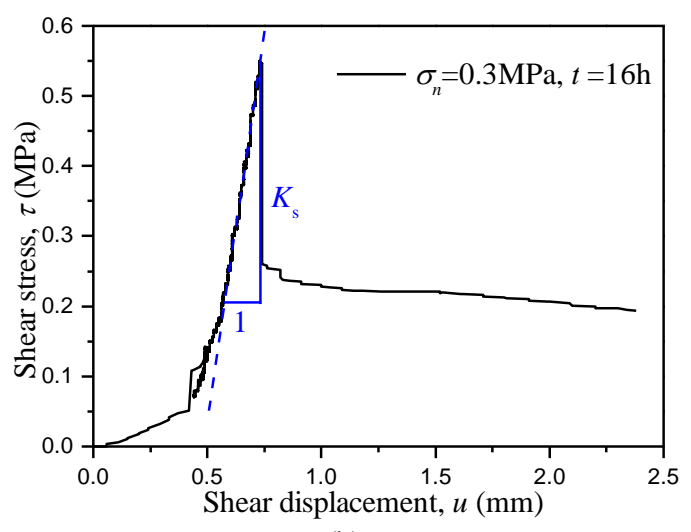

(b)

Figure 10: (a) The test results of very early-aged samples; (b) The results of samples with longer curing time

During the shear tests, two typical shear behaviors were observed (Fig. 10a, b). For the samples with very short curing time (e.g. $8 \mathrm{~h}$ ), the bond interface showed gradual failure, and the shear stress reduced gradually after the peak value; while for the samples with longer curing time (e.g. $16 \mathrm{~h}$ and above), the curves showed sudden drops after the peak shear stress. The difference might be attributed to brittleness of shotcrete after a longer period of curing time, and it was also a kind of fundamental property of the bond interface. 
Time-dependent shear strength of bond interface

The relationships between peak shear stress and normal stress from the experimental results for different curing time were illustrated in Fig. 11 through linear fitting. The shear cohesion and friction angle of the interfaces of different ages were obtained, when the Mohr-Coulomb failure criterion was applied. To regress the time-dependent behaviors of the interfacial shear properties, different equations were attempted for curve fitting as presented in Fig. 12 and Fig. 13.
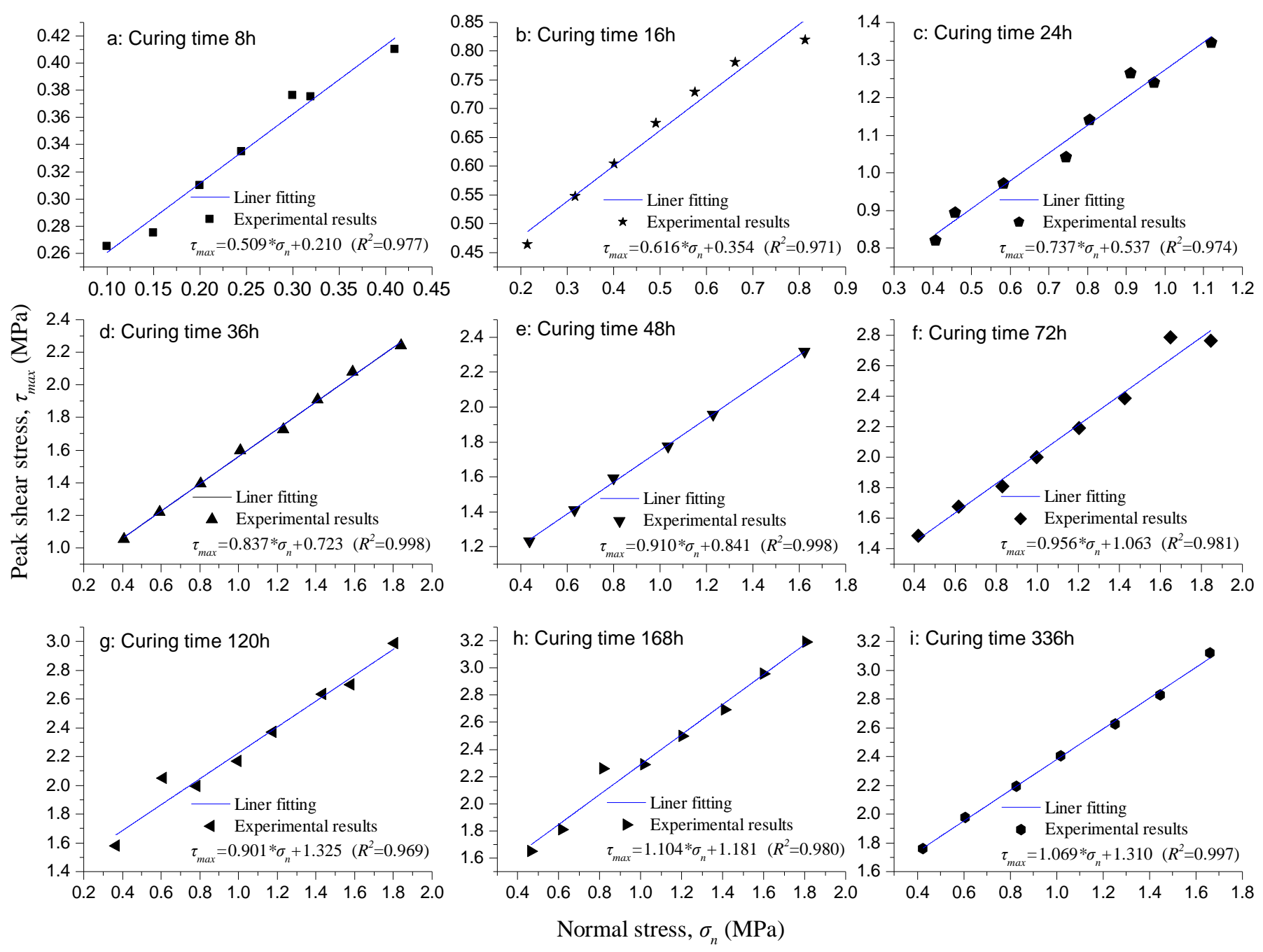

Figure 11: Relationship between peak shear stress and normal stress of interfaces at different curing time

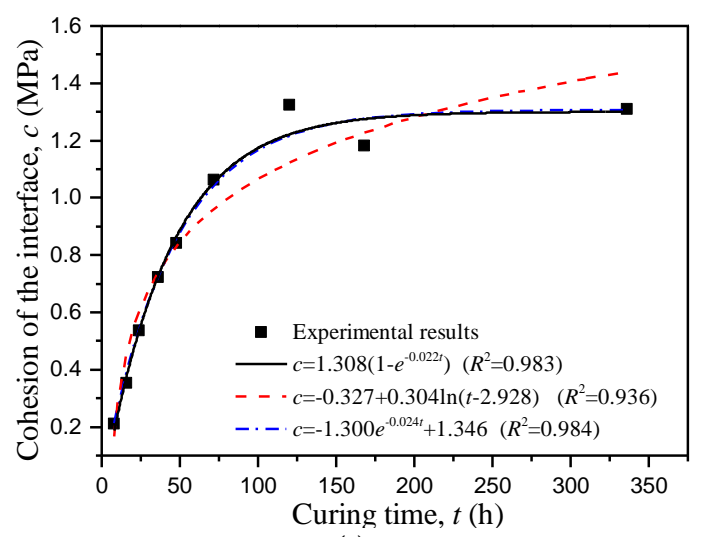

(a)

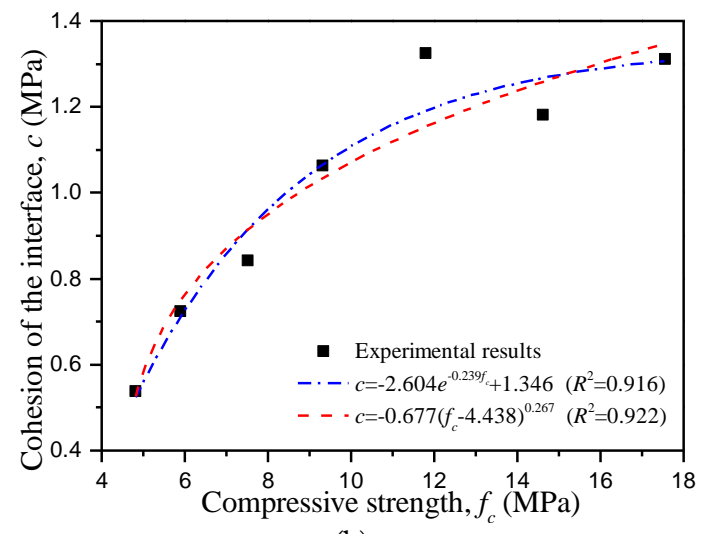

(b)

Figure 12: (a)Time-dependent shear cohesion of interface; (b) Compressive strength vs. shear cohesion of interface 


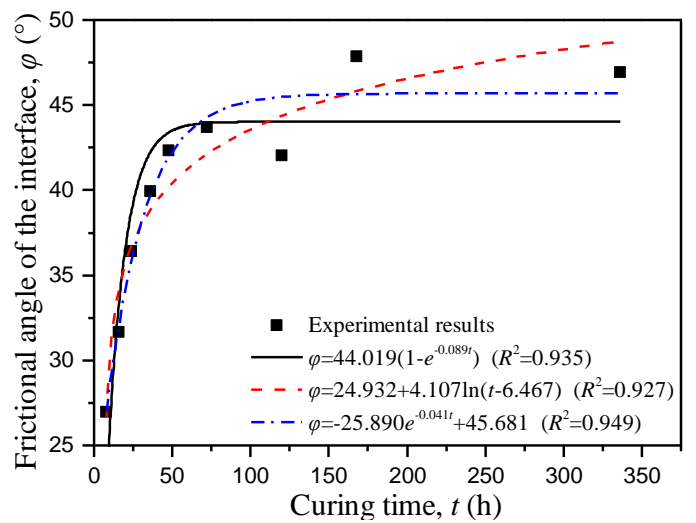

(a)

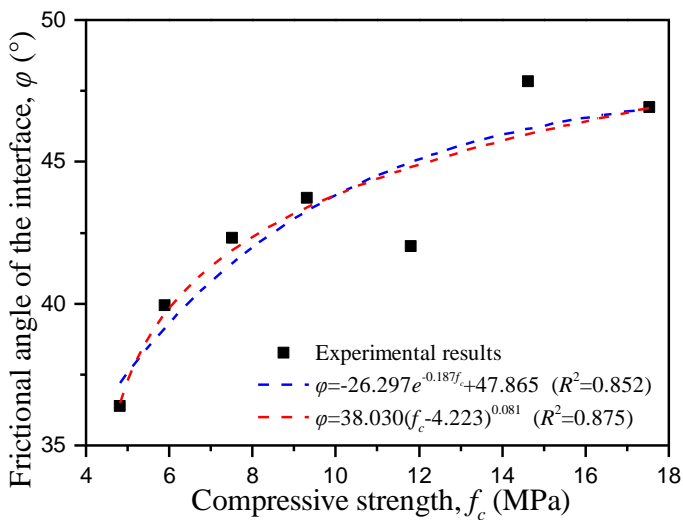

(b)

Figure 13: (a)Time-dependent shear fraction of interface; (b) Compressive strength vs. shear friction of interface

As shotcrete hardened, both the cohesion and frictional angle of rock-shotcrete interface showed strong time-dependent behaviors and rapid growth in the early ages (e.g. before $120 \mathrm{~h}$ ). After $120 \mathrm{~h}$, both cohesion $c$ and frictional angle $\varphi$ grew smoothly which was similar to the mechanical properties of shotcrete [21-22]. Oreste [23] suggested that, the timedependent properties of shotcrete could be simulated by Eq.(1).

$$
M_{t}=M_{0}\left(1-e^{\alpha t}\right)
$$

where $M_{t}$ is a mechanical property at curing time of $\mathrm{t}, M_{0}$ is the final property for $t=\infty$, and $\alpha$ is a time constant for different mechanical properties.

Two other types of curve fitting were carried out for the time-dependent behaviors of cohesion and frictional angle, which were suggested by the following two equations.

$$
\begin{aligned}
& M_{t}=a+b \ln (t+c) \\
& M_{t}=a+b e^{-c t}
\end{aligned}
$$

Both the time-dependent behaviors of cohesion and frictional angle of the interface at different curing time could not be regressed by Eq.(2) very well as shown in Fig. 12a and Fig. 13a, when compared with the results from Eq.(1). Although Eq. (2) was suggested by Bae et al. [15] to simulate the uniaxial compressive strength of shotcrete of a certain period (between 1 day and 30 days), the regressions of time dependent behaviors of cohesion and frictional angle of the interface by Eq.(2) seem to be not very well, and the increase after $336 \mathrm{~h}$ predicted by Eq.(2) could not be neglected.

For more reasonable simulation of the time-dependent interfacial cohesion and frictional angle, Eq.(3) was modified based on Eq.(1) and adopted for curve fitting. The results showed that, both the cohesion and frictional angle of the bond interface followed the regression by Eq.(3) at a good level.

Since interfacial shear properties between shotcrete and rock substrate were time-dependent, as well as the compressive strength of shotcrete, there might be some relationships between them. During the direct shear test, the compressive strength of shotcrete at curing time of $24 \mathrm{~h}, 36 \mathrm{~h}, 2 \mathrm{~d}, 3 \mathrm{~d}, 5 \mathrm{~d}, 7 \mathrm{~d}$ and $14 \mathrm{~d}$ was tested, since the shotcrete cubes younger than $24 \mathrm{~h}$ was hard to demold. The time-dependent development of compressive strength could be regressed by Eq.(1) at a reasonable level, as presented in Fig. 14. The relationships between interfacial shear strength and compressive strength of shotcrete were regressed and demonstrated in Fig. 12b and Fig. 13b. It seems that, the proposed Eq.(3) could regress the relationships at an acceptable level, and the equation determined by Eq.(1) and Eq.(3) seems to better for such regressions. By regressing the relationship between interfacial shear strength and compressive strength of shotcrete, the interfacial shear strength could easily obtain in practical use like numerical models and analytical solutions.

\section{Time-dependent shear stiffness of bond interface}

The shear stiffness of bond interface is affected by shotcrete mechanical properties, rock type, curing time [15] and surface roughness of rock [19]. To reveal the relationship between shear stiffness and curing time, all the factors excluding curing time of shotcrete were nearly the same in this study. Interfacial shear stiffness for all the samples were calculated as 
the slopes of the sections where shear stress increases almost linearly with respect to shear displacement in $u-\tau$ curves, as the blue dash line demonstrated in Fig. 10, and the relationship is presented in Fig. 15a.

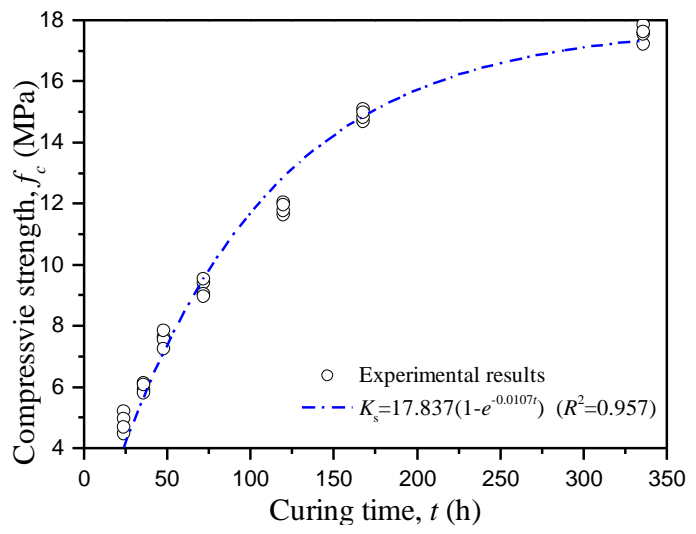

Figure 14: Time-dependent compressive strength of shotcrete.

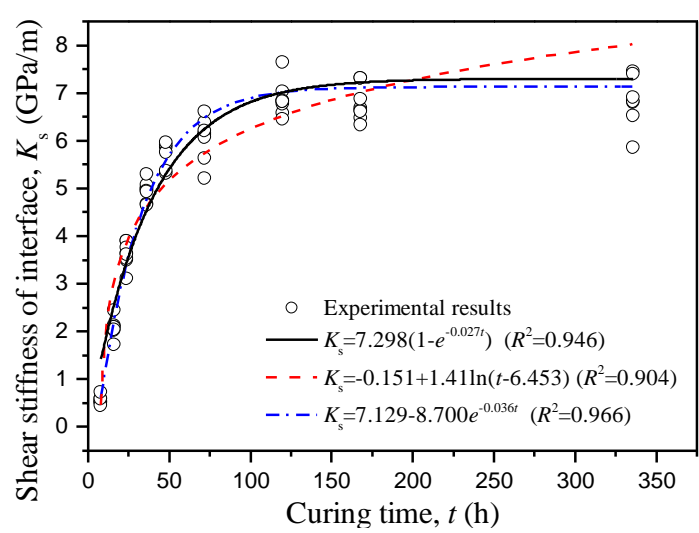

(a)

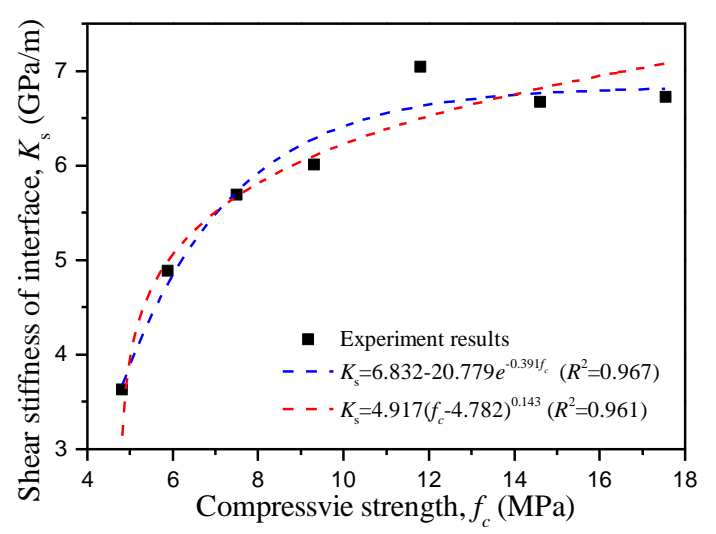

(b)

Figure 15: (a)Time-dependent shear stiffness of interface; (b)Compressive strength vs. shear stiffness of interface

The shear stiffness of the interface was found to grow quickly during the first $72 \mathrm{~h}$, while after $120 \mathrm{~h}$, the shear stiffness seemed to grow very little (Fig. 15a), which was similar to the behaviors of shear strength. Three types of curve fitting were carried out suggested by Eq.(1) (3), and it's found that, the logarithm equation was not suitable for simulating the time-dependent behaviors of shear stiffness, since the stiffness of the samples younger than $8 \mathrm{~h}$ could not be regressed. When the exponential functions were applied, it could well be regressed. Besides, the 3-parameter exponential function provided a better regression than the 2-parameter one.

Based on the comparison of the 3 functions in the curve fitting for shear strength and shear stiffness, the 3-parameter exponential function was found to be more suitable and accurate for simulating the time-dependent behaviors of shear strength and stiffness, especial for the early-aged samples compared with the 2-parameter one.

Interfacial shear stiffness could be represented by compressive strength of shotcrete with certain regressions. Two equations were used to regress to relationship between shear stiffness and compressive strength, Eq. (3) and a combination of Eq. (1) and (3) in detail (Fig. 15b). It could be seen that, the regression by Eq. (3) was a little better than that by the combination of Eq. (1) and (3), which is different from the regression case of interfacial shear strength.

\section{Shear failure modes of the bond interface}

During the direct shear tests, two failure types were observed. Full shear bond failures were observed for about $89.6 \%(60$ out of 67) of the samples, and for the other samples, part of shotcrete failed and remained on the rock substrate. The percentages of failure modes for different aged samples were summarized in Fig. 16. For samples aged between $72 \mathrm{~h}$ and $168 \mathrm{~h}$, shotcrete failure was observed at each age, while for samples at other ages, only shear failure along the interface occurred. 


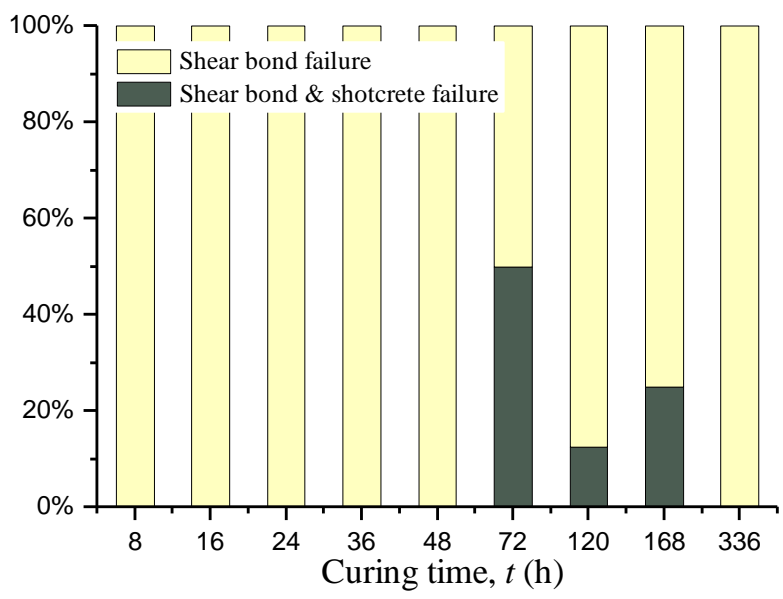

Figure 16: Failure modes of different aged samples

The area ratios of failed shotcrete were calculated as illustrated in Fig. 17, and the ratio of shotcrete remained on rock substrate exceeded $17.3 \%$ for no samples. The failure zone of shotcrete was near the edge toward to the shear direction.

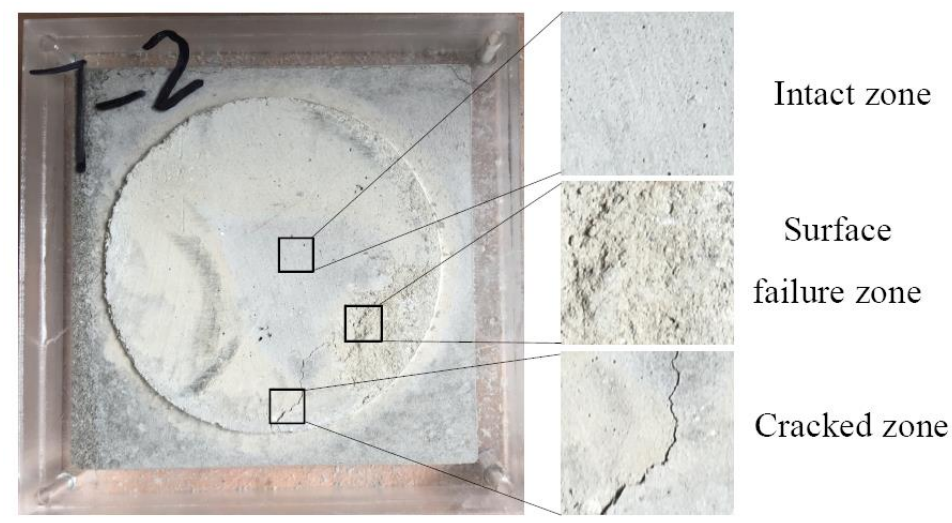

Figure 17: Shear failure modes of shotcrete at interface.

It's clear in Fig. 17 that, the failure of interface could be described as three kinds of zones, and the main one should be the intact zone, which means no shotcrete were remained on the rock substrate and the failure of the bond interface was along the interface. The second kind one should be the surface failure zone, which means some shotcrete were remained on the rock substrate. The third one should be the cracked zone, which means the shotcrete was cracked with certain depth and even to the other surface. From the three kind of failure zones, it could be inferred that, the failure of rockshotcrete bond interface in shear direction is a very complicated process, which involves in not only the properties of bond interface, but also the failure mechanism of materials.

\section{Discussion on the newly developed test method}

The newly developed test method for rock-shotcrete interfacial shear properties is reliable and suitable for use in laboratory environments. The method focused on the accuracy during the sample preparation process, especially with drilling rock substrate before shotcreting and making individual sample cells. The main advantage of the method is that, the samples of early age would not be subjected to shock and vibration in the drilling or sawing process which could cause damages to the bond interface.

Another feature of the method is that, the position of the interface can be accurately guaranteed, so that the shear failure could occur just at the interface and the "real" shear properties of the interface can be evaluated. Besides, the inner size of shotcrete housing dock was designed bigger than that of the rock core, so that the two materials could be fully bonded at the interface. 
The assembly of RCPA and SHD were remained around the sample, which made it easier for shear test, without demoulding process. However, the load was not applied on shotcrete directly, but on the right side of the Perspex mould (Fig. 8a), which could cause strain in the mould. As the interfacial shear stiffness was defined as the ratio of shear stress to shear displacement, the strain in the mould would affect the obtained interfacial shear stiffness. The strain can be described with Eq.(4):

$$
\varepsilon=F_{s} / E A
$$

where $\varepsilon$ is the strain in the part of mould where the shear load applied, $F_{s}$ is the peak shear load, the elastic modulus of Perspex $E=2.9 \mathrm{GPa}$, and the area of the mould contacting with shear machine $A=4000 \mathrm{~mm}^{2}$. The deformation of the mould during shearing could be calculated by using Eq.(5).

$$
\Delta L=L \varepsilon=L F_{s} / E A
$$

where $\Delta L$ is the change in length of the mould and $L=15 \mathrm{~mm}$ is the original length.

When testing the early-aged samples, the shear load was rather low, and thus the deformation of the mould was quite small compared with the whole shear displacement. For example, for the sample tested at $16 \mathrm{~h}$ and $0.8 \mathrm{MPa}$ of normal load, the maximum shear stress $\tau_{\max }=0.82 \mathrm{MPa}$, and the corresponding deformation of the mould was $0.008 \mathrm{~mm}$, just $1.3 \%$ of the total shear displacement. While for the sample tested at $336 \mathrm{~h}$ and $1.65 \mathrm{MPa}$ of normal load, the overestimated shear displacement was $0.031 \mathrm{~mm}$, about $4.5 \%$ of the total shear displacement, and thus the shear stiffness of the hardened samples might be underestimated a bit.

In addition, some energies were gathered in the mould during the tests, and the shear displacement on the interface increased too quickly than expected after failure due to energy released from the mould. For this reason, no residual friction were obtained as the shear behaviors was not quasi-static any more. To eliminate the underestimation of shear stiffness and to evaluate the residual friction of the rock-shotcrete interface, the right part of SHD could be replaced by other much stiffer materials like steel or iron, which could be the main improvement to be made in the following research.

\section{CONCLUSIONS}

A new test method for the evaluation of the rock-shotcrete interfacial shear properties was developed in this paper, in which the shock and vibration effects were eliminated compared with the previous methods, and thus the shear properties could be tested more accurately, especially for the bond interface formed by early-aged shotcrete and rock. Based on the method described above and test results presented, the following conclusions can be drawn:

(1) The newly developed method for testing the rock-shotcrete interfacial shear properties was based on a new principle that the rock used for substrate was prepared before shotcreting and the test samples were made as individual cells. This method was proved to be an easy and stable way to evaluate the properties compared with the previous ones.

(2) The new set of mould that following the new test principle was designed with simple assemblies and made of Perspex with low costs, which made it possible for wide usage. With the newly designed mould, unlimited samples could be made at the same time for testing. The set of mould, however, was just an example designed for a special test machine, and could be modified for other shear test machines easily.

(3) With the newly developed test method and mould, the very early-aged $(8 \mathrm{~h})$ rock-shotcrete interfacial shear properties were successfully tested. The time-dependent shear properties of rock-shotcrete interface were revealed and regressed by using different functions. The regression results showed that, the time-dependent behaviors of interfacial shear strength and stiffness could be simulated by the same type of function with different parameters. And both the interfacial shear strength and stiffness could be represented by compressive strength of shotcrete through simple equations, which could offered an easy way for practical use of the interfacial properties.

(4) As the shear load was applied to shotcrete through the mould on the right side, the deformation of the mould could not be neglected, which could lead to underestimation of the interfacial shear stiffness. In addition, the energies gathered in the mould could destroy the quasi-static shear behaviors after peak shear stress, and thus no residual friction coefficient was obtained. However, the deficiency of the mould could be avoided by replacing part of the SHD with steel, so that the deformation of the mould and energies gathered in the mould could be eliminated, which could be the direction of further researches of this method. 


\section{ACKNOWLEDGMENTS}

his work was sponsored by the National Natural Science Foundation of China (No. 51378436, No. 51678501, and
No. 51778540) and the National Key Research and Development Program of China (2016YFB1200401).

\section{REFERENCES}

[1] Guan, B.S. (2009). Shotcrete technology for tunneling and underground engineering. Beijing, China Communications Press.

[2] Malmgren, L. and Nordlund, E. (2008). Interaction of shotcrete with rock and rock bolts - a numerical study, International Journal of Rock Mechanics and Mining Sciences, 45(4), pp. 538-553.

[3] Nwoji, C.U., Onah, H.N., Mama, B.O. and Ike C.C. (2018). Ritz variational method for bending of rectangular kirchhoff plate under transverse hydrostatic load distribution, Mathematical Modelling of Engineering Problems, 5(1), pp. 1-10.

[4] Bryne, L.E., Ansell, A. and Holmgren, J. (2014). Laboratory testing of early age bond strength of shotcrete on hard rock, Tunnelling and Underground Space Technology Incorporating Trenchless Technology Research, 41, pp. 113119.

[5] Tian, H., Chen, W., Yang, D., Wu, G. and Tan, X. (2016) Numerical analysis on the interaction of shotcrete liner with rock for yielding supports, Tunnelling and Underground Space Technology, 54, pp. 20-28.

[6] Lee, S.D. (2010). Numerical analysis for irregular shotcrete on uneven tunnel perimeter, International Journal of Rock Mechanics and Mining Sciences, 47(3), pp.488-495.

[7] Ansell, A. (2005). Recommendations for shotcrete on rock subjected to blasting vibrations, based on finite element dynamic analysis, Magazine of Concrete Research, 57(3), pp. 123-133.

[8] Ansell, A. (2007). Dynamic finite element analysis of young shotcrete in rock tunnels, ACI Structural Journal, 104(1), pp. 84-92.

[9] Bryne, L. E., Ansell, A. and Holmgren, J. (2014). Laboratory testing of early age bond strength between concrete for shotcrete use and rock, Nordic Concrete Research, pp. 81-100.

[10] Malmgren, L., Nordlund, E. and Rolund, S. (2005) Adhesion strength and shrinkage of shotcrete, Tunnelling and Underground Space Technology incorporating Trenchless Technology Research, 20(1), pp. 33-48.

[11] EFNARC. (1996). European specification for sprayed concrete.

[12] Bernard, E.S. (2008). Early-age load resistance of fibre reinforced shotcrete linings, Tunnelling and Underground Space Technology Incorporating Trenchless Technology Research, 23(4), pp. 451-460.

[13] Thomas, A. (2009). Spayed concrete lined tunnel, London and New York, Taylor and Francis Group.

[14] Saiang, D., Malmgren, L. and Nordlund, E. (2005). Laboratory tests on shotcrete-rock joints in direct shear, tension and compression, Rock Mechanics and Rock Engineering, 38(4), pp. 275-297.

[15] Bae, G.J., Chang, S. H., Lee, S.W. and Park, H.G. (2004). Evaluation of interfacial properties between rock mass and shotcrete, International Journal of Rock Mechanics and Mining Sciences, 41(3), pp. 106-112.

[16] Sadki, A., Younes, R., Bradai, M.A., Hattali, M.L. and Mesrati, N. (2016). Microstructure and interfacial strength of stainless steel coatings obtained by thermal spray process, Annales de Chimie: Science des Materiaux, 40(3-4), pp. 131-142.

[17] Li, X., Tang, C., Wang, Q., Li, X.P. and Hao J. (2017). Molecular simulation research on the micro effect mechanism of interfacial properties of nano $\mathrm{SiO} 2 /$ meta-aramid fiber, International Journal of Heat and Technology, 35(1), pp. 123-129.

[18] Wang, J.L., Zhang, S.H., Peng, F.F. (2018). Influence mechanism of hard brittle grits on the drilling performance of diamond bit, Annales de Chimie - Science des Matériaux, 42(2), 209-220.

[19] Meng, H., Wei, J., Xing, L.X. (2018). Permeability and mechanical properties of basalt fiber-reinforced concrete under magnesium sulfate corrosion, Revue des Composites et des Matériaux Avancés, 28(3), 333-343.

[20] Qiao, Q., Nemcik, J., Porter, I. and Baafi, E. (2015). Laboratory tests on thin spray-on liner penetrated rock joints in direct shear, Rock Mechanics and Rock Engineering, 48, pp. 2173-2177.

[21] Chang, Y. (1992). The influences of the early age properties of shotcrete on tunnel lining, Journal of Yangtze River Scientific Research Institute, 9(3), pp. 8-16. 
[22] Hellmich, C., Ulm, F.J., Mang, H.A. (1999). Multisurface chemoplasticity. I: Material model for shotcrete, Journal of Engineering Mechanics, 125(6), 692-701.

[23] Oreste, P.P. (2003). A procedure for determining the reaction curve of shotcrete lining considering transient conditions, Rock Mechanics and Rock Engineering, 36(3), pp. 209-236.

[24] Gao, S.Y. and Tang, X.N. (2018). Impact mechanism of marine biofilm on concrete durability, Chemical Engineering Transactions, 64, 613-618. 